\title{
Commentary: Surgery or radiotherapy for colorectal lung metastases: Does it really matter?
}

\author{
Tom Treasure, MD, MS, FRCS, FRCP, ${ }^{a}$ and Fergus Macbeth, DM $^{\mathrm{b}}$
}

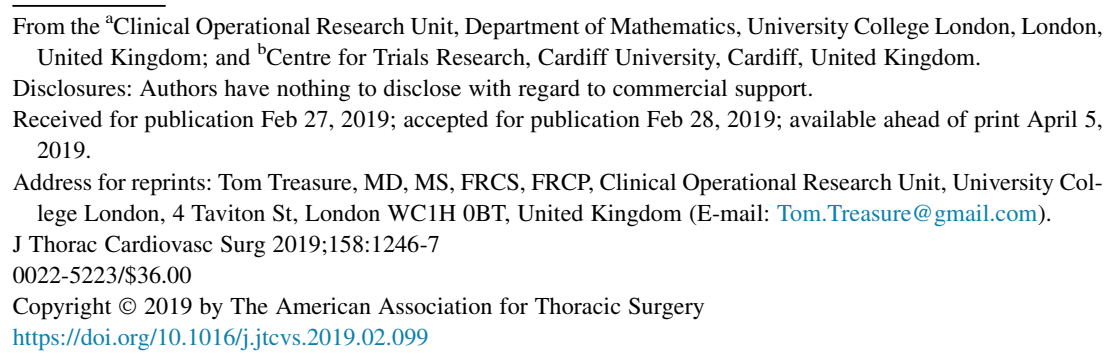

This issue of the Journal includes a retrospective study comparing the efficacy of surgical resection and stereotactic radiotherapy (SBRT) in the management of lung metastases in patients with colorectal cancer (CRC). ${ }^{1}$ The unit of investigation was the lung nodule, and the primary outcome is local recurrence assessed by radiologic appearance. The headline result is that surgery appears significantly more efficacious than SBRT. But this was a retrospective case record study with marked differences in the numbers and the clinical characteristics of the 2 groups. Despite thorough propensity matching and adjustment to allow a legitimate comparison, concerns must remain about the reliability of the conclusion because of residual confounding and "unknown unknowns." Cited by the authors ${ }^{2}$ is a published study from their institution, pooling data from 2 randomized controlled trials of SBRT versus surgery for lung cancer. It was met with scorn in an "Expert Opinion" in the Journal. $^{3}$ This will have been daunting for those contemplating trials, but still, the best way of removing lung metastases can only be answered conclusively by a randomized controlled trial.

But does the result matter anyway? The aim of any treatment must be to improve relevant clinical outcomes. Is local recurrence a meaningful outcome? Removal of individual lung metastases, which are almost always asymptomatic, is unlikely to be of palliative benefit and it remains uncertain whether or not it improves survival, despite the widespread belief that it does. We have argued before that the observational evidence underpinning this belief is unreliable because of selection bias, immortal time bias, and inadequate controls. ${ }^{4}$ Is this "pillar of modern thoracic surgery" built on solid evidence or sand $?^{5}$ The results of the randomized Pulmonary Metastasectomy in Colorectal Cancer (PulMiCC) trial will be published soon and may throw some light on this. We already know that increased surveillance of patients with CRC

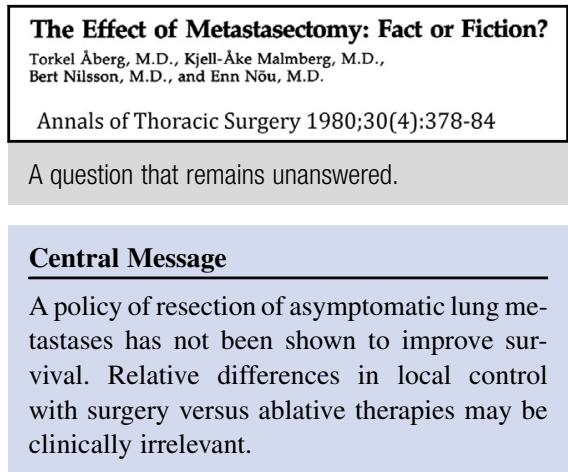

See Article page 1234. for metastatic disease may detect metastases sooner and leads to more intervention, but does not improve overall survival. ${ }^{6,7}$

The study by Nelson ${ }^{1}$ fails to provide any survival data. For wedge resection, which dominates the study, the median number of metastases was 3 and the median interval since resection of the primary was 1.3 years. Multiple metastases and shorter intervals are indicators of poor survival after metastasectomy. ${ }^{8}$ Many patients had these adverse prognostic features. It is likely that the majority of patients in this series died of disseminated CRC. Neither thoracoscopic surgery nor SBRT for lung metastases is a risk-free intervention. Without clear evidence of a survival benefit, how many of these 826 interventions were truly worthwhile? As well as there perhaps being a waste of clinical resources in carrying out these treatments, there may well have been a waste of research time and effort in trying to answer a question of doubtful clinical relevance. ${ }^{9}$ Torkel Åberg's 39-yearold question remains unanswered.

\section{References}

1. Nelson DB, Tayob N, Nguyen Q-N, Erasmus J, Mitchell KG, Hofstetter WL, et al. Local failure after stereotactic body radiation therapy or wedge resection for colorectal pulmonary metastases. J Thorac Cardiovasc Surg. 2019;158:1234-41.e16.

2. Chang J, Senan S, Smit ERJ. Surgery versus SABR for resectable non-small cell lung cancer. Lancet Oncol. 2015;16:e374-5.

3. Meyers BF, Puri V, Broderick SR, Samson P, Keogan K, Crabtree TD. Lobectomy versus stereotactic body radiotherapy for stage I non-small cell lung cancer: post hoc analysis dressed up as level-1 evidence? J Thorac Cardiovasc Surg. 2015;150: 468-71.

4. Treasure T, Macbeth F. Is surgery warranted for oligometastatic disease? Thorac Surg Clin. 2016;26:79-90.

5. Schirren J, Schirren M, Lampl L, Sponholz S. Surgery for pulmonary metastases: quo vadis? Eur J Cardiothorac Surg. 2017;51:408-10. 
6. Jeffery M, Hickey BE, Hider PN. See AM. Follow-up strategies for patients treated for non-metastatic colorectal cancer. Cochrane Database Syst Rev. 2016;11:CD002200.

7. Mokhles S, Macbeth F, Farewell V, Fiorentino F, Williams NR, Younes RN, et al. Meta-analysis of colorectal cancer follow-up after potentially curative resection. Br J Surg. 2016;103:1259-68.
8. Onaitis MW, Petersen RP, Haney JC, Saltz L, Park B, Flores R, et al. Prognostic factors for recurrence after pulmonary resection of colorectal cancer metastases. Ann Thorac Surg. 2009;87:1684-8.

9. Glasziou P, Chalmers I. Research waste is still a scandal-an essay by Paul Glasziou and Iain Chalmers. BMJ. 2018;363:k4645. 